\title{
The Effects of Severe Plastic Deformation on some Properties Relevant to Ti Implants
}

\author{
Anibal Andrade Mendes Filho*, Vitor Luiz Sordi, Maurizio Ferrante \\ Department of Engineering Materials, Federal University of São Carlos - UFSCAR, \\ Rod. Washington Luis, Km 235, CEP 13565-905, São Carlos, SP, Brazil
}

Received: February 21, 2011; Revised: October 19, 2011

\begin{abstract}
In some types of surgical implants, such as bone screws and plates, Grade $2 \mathrm{Ti}$ is seriously considered as a replacement for the Ti-6Al-4V alloy. Advantages are lower cost and the absence of $\mathrm{Al}$ and $\mathrm{V}$, which have been identified as potentially harmful to human health. The present paper shows that the lower strength of the commercially pure metal can be enhanced by Severe Plastic Deformation followed by conventional cold rolling, so as to reach a strength level higher than the technical requirements applicable to the alloy. This was ascertained by tensile and Vickers hardness tests from which it was concluded that the best combination of properties are obtained by submitting the metal to Equal Channel Angular Pressing (four passes at $300{ }^{\circ} \mathrm{C}$ ) followed by a $70 \%$ thickness reduction by cold rolling. Although the present results are valid for the material only, and not for the product considered, that is, bone screws, it appears that this solution is a step towards the replacement of the Ti6-4 alloy by Grade $2 \mathrm{Ti}$, at least for some types of metallic medical implants.
\end{abstract}

Keywords: ECAP, cold rolling, titanium, orthopaedic implants, bone screws

\section{Introduction}

Surgical implants make intensive use of the well known Ti-6Al-4V alloy. Cost consideration and concerns regarding the effect of $\mathrm{Al}$ and $\mathrm{V}$ on human health constitute a strong motivation for the replacement of said alloy ${ }^{1}$, and a viable candidate is the lower cost Ti Grade 2, from which a better corrosion resistance is expected, although its tensile strength compares unfavorably with that of the alloy, viz. $350 \mathrm{MPa}$ against $1000 \mathrm{MPa}$.

The main effect of any Severe Plastic Deformation (SPD) technique is the increase of mechanical strength due to grain size reduction, and among those techniques only Equal Channel Angular Pressing (ECAP) is capable of producing billets of commercial dimensions. Besides the Hall-Petch effect, grain size reduction exerts a positive effect on two important requirements of implant materials: i) osteoblasticity, a phenomenon related to the integration of the implant with the surrounding bone tissue ${ }^{2}$, and ii) fatigue strength ${ }^{3}$.

As for the effects of ECAP on Ti and its alloys, there is a fair amount of information. For instance, a recent paper by $\mathrm{Zhao}^{4}$ shows that, contrarily to previous assumptions ${ }^{5}$, Ti can be deformed at room temperature, and eight passes in a $120^{\circ}$ die were thus carried out. This process reduced the grain size from 23 to $0.2 \mu \mathrm{m}$ and as a consequence the yield strength was raised to $710 \mathrm{MPa}$, that is, a $160 \%$ increase over that of annealed Grade $1 \mathrm{Ti}$. The authors emphasize that reduction of pressing speed is a key detail to successfully deform $\mathrm{Ti}$ at room temperature. However, the literature mentions many instances of higher tensile properties when warm ECAP deformation is followed by cold rolling; Thus Stolyarov $^{6}$ and collaborators obtained final yield strength equal to $1020 \mathrm{MPa}$ but only 6\% elongation. Recalling

*e-mail: anibalmendes@gmail.com.br that ECAP performed at room temperature resulted in an elongation of $19 \%{ }^{4}$, this procedure appears to be more advantageous than the sequence - warm ECAP plus cold rolling-except when pressing forces are considered.

The relationship between strain level, grain size and strength is illustrated in a number of papers. For instance ${ }^{7}$ it was shown that grain refinement mainly takes place after the first pass, saturation being reached by the sixth and eighth passes. This confirms previous findings by Langdon ${ }^{8}$ which were obtained on $\mathrm{Al}$ samples. It is important to point out that this effect of the first pass on grain size appears to be a fundamental occurrence, not confined to this or that material. As for the influence of strain level on strength, Table 1, reproduced from a recent investigation, shows a relatively slow evolution of hardness with pass number, except when the first pass is considered ${ }^{9}$. ECAP deformation was carried out at $300^{\circ} \mathrm{C}$ in a $120^{\circ}$ die, following route $\mathrm{B}_{\mathrm{c}}$; after four passes the grain size was reduced from 28 to $0.25 \mu \mathrm{m}$.

To understand the apparent inconsistency between the statement that the grain size is defined by the first pass and the observed increase - although slow - of the hardness, hence of tensile strength, it may be useful to summarize the present knowledge regarding grain refinement mechanisms. The basic model describes the formation of a banded structure of elongated subgrains, which under increasing strain transform into an equiaxed array of grains ${ }^{10}$. This transition from subgrains to grains is in actual fact a transition from low angle boundaries $\left(2 \leq \xi<15^{\circ}\right)$ to high angle boundaries $\left(\xi \geq 15^{\circ}\right)$ a phenomenon which is currently under intense study. For instance, using Electron BackScattered Diffraction (EBSD) the evolution from low to high angle boundaries was followed on ECAP deformed samples of commercial Al. After one pass the proportion of the latter type of boundaries was $15 \%$, a figure which doubled after 
four passes ${ }^{11}$. Additionally, the same investigation correlated tensile strength with grain boundary character and concluded that strength increases with the proportion of high angle boundaries. This result suggests that such microstructural features, sometimes called "non-equilibrium boundaries", can be more efficient in limiting plastic flow than low angle boundaries, and a possible explanation is that they would experience difficulties to emit dislocations into the neighboring grain ${ }^{12}$. Of course, final strength is dictated not only by the above described action of the grain boundaries, but also by dislocation hardening. On this respect a recent calculation performed on a ECAP-deformed Al-4\% Cu alloy showed that grain boundaries and dislocation hardening, account for 54 and $20 \%$ of the total strength, respectively, the balance being attributed to precipitation hardening ${ }^{13}$.

Finally, it must be recalled that, besides the positive effects above discussed, grain size reduction to submicron level enhances the corrosion resistance of commercial $\mathrm{Ti}$, as observed by Balyanov et al. on commercially pure $\mathrm{Ti}^{14}$.

The present work is directed to the upgrading of the mechanical strength of Grade $2 \mathrm{Ti}$, using a SPD sequence composed by ECAP followed by cold rolling (CR). After a preliminary discussion regarding the effect of such process on Grade 2 Ti tensile behavior, the feasibility of using that material in the manufacture of cortical screws will be analyzed.

\section{Experimental}

\subsection{Material}

Grade $2 \mathrm{Ti}$, with chemical composition complying with the ASTM B $348^{15}$ Standard. From the initial extruded and annealed bar, samples $\varnothing 10$ and $70 \mathrm{~mm}$ length were machined out and reannealed at $710^{\circ} \mathrm{C} / 2$ hours, in order to guarantee a homogeneous grain size.

\subsubsection{ECAP deformation and CR}

The former was conducted at $300{ }^{\circ} \mathrm{C}$ in a $\Phi=120^{\circ}$ die constructed with heat resisting steel. ECAP deformation consisted of four passes following Route $\mathrm{B}_{\mathrm{C}}$ (sample rotated $90^{\circ}$ clockwise between passes) at ram speed of $\approx 5 \mathrm{~mm} / \mathrm{min}$. Additionally a one pass experiment was performed at room temperature. Samples identification scheme is in Table 2.

Additionally, samples in the non-deformed (0X) and ECAP-deformed condition $(4 \mathrm{XH})$ were cold rolled up to a thickness reduction equal to 70 and $90 \%$. Identification was the same shown in Table 2, followed by the letters CR; numbers within parenthesis indicate the thickness reduction $(70,90 \%)$. Rolling was performed in a PFENN dual rolling mill with a linear speed of $300 \mathrm{~mm} / \mathrm{s}$.

\subsection{Mechanical tests}

\subsubsection{Tensile and hardness}

Miniature specimens having $8 \mathrm{~mm}^{2}$ section and $12 \mathrm{~mm}$ gauge length were tested in an INSTRON D5500 machine at a deformation rate equal to $10^{-3} / \mathrm{s}$. The tensile samples were cut along the longitudinal axis of the ECAP billet and along the rolling direction. Data on yield and ultimate
Table 1. Vickers hardness of Grade 2 Ti after ECAP'.

\begin{tabular}{ccc}
\hline Condition & $\begin{array}{c}\text { Nominal } \\
\text { equivalent strain }\end{array}$ & HV 20 \\
\hline Coarse-grained & - & 145 \\
1 pass & 0.66 & 205 \\
2 passes & 1.32 & 208 \\
3 passes & 1.98 & 213 \\
4 passes & 2.64 & 269 \\
\hline
\end{tabular}

Table 2. Samples identification and ECAP deformation modes.

\begin{tabular}{cc}
\hline Sample & Condition \\
\hline $0 \mathrm{X}$ & Annealed \\
$1 \mathrm{X}$ & Annealed, one pass room temperature \\
$1 \mathrm{XH}$ & Annealed, one pass at $300^{\circ} \mathrm{C}$. \\
$4 \mathrm{XH}$ & Annealed, four passes at $300^{\circ} \mathrm{C}$. \\
\hline
\end{tabular}

strength and on uniform and total elongation are the average of at least two tensile tests per condition. Vickers hardness measurements were performed under a load of $0.20 \mathrm{kN}$ and each value is the average of four measurements.

\section{Results and Discussion}

Table 3 summarizes the results of the tensile and hardness tests. For each condition differences between maximum and minimum $\sigma_{u}$ are less than $5 \%$. Comparison of samples $1 \mathrm{X}$ and $1 \mathrm{XH}$ shows that, although yield and maximum tensile strength are almost identical, the hot deformed sample exhibits a much higher ductility, viz $22 \%$ strain to fracture against $11 \%$. This suggests that room temperature ECAP may not be ideal when compared with warm ECAP, provided that in this latter case deformation temperature is kept below levels which would promote softening mechanisms. On this respect $300^{\circ} \mathrm{C}$ seems to be ideal since analysis of the tensile behavior of the present samples suggests only a small amount of recovery ${ }^{6}$, but the residual stresses appear to be reduced and as a result strength is unchanged whilst elongation is considerably increased. Studies employing cold rolling as a deformation mode showed that below $600{ }^{\circ} \mathrm{C}$ recrystallization is negligible ${ }^{16}$ besides, $300{ }^{\circ} \mathrm{C}$ corresponds to a homologous temperature close to 0.3 , which is insufficient for static recrystallization.

Figure 1 shows ultimate stress $\left(\sigma_{\mathrm{u}}\right)$ and elongation at rupture $\left(\varepsilon_{\mathrm{t}}\right)$ for each experimental condition. When compared with the coarse-grained Grade $2 \mathrm{Ti}$, a harmful effect on ductility is observed in all samples subjected to SPD, although values are still above the minimum that ASTM F136 ${ }^{17}$ specifies for the alloy Ti6-4. Summarizing: when compared with the Ti6-4 alloy all SPD conditions give a higher ductility, and one of them, namely the 4XHCR(70) sample, a higher strength Another important observation is that ductility losses are much higher when DPS does not include ECAP.

Comparison of the present results with literature data is shown in Figure 2. It can be seen that, although the strength 
of the Ti6-4 alloy has not yet been reached, the combination of properties here obtained is very good. Indeed; whilst the tensile strength obtained by Stolyarov et al. ${ }^{6,18}$ is higher, the corresponding ductility is quite low, with total elongation below $10 \%$.

In order to use DPS processed Grade $2 \mathrm{Ti}$ in the manufacture of the cortical screws type HA 3.5, as identified by the ASTM F543 Standard ${ }^{20}$ it is necessary to comply with

Table 3. Tensile data of Grade 2 Ti under different processing conditions.

\begin{tabular}{cccccc}
\hline Sample & $\begin{array}{c}\sigma_{\mathbf{y}} \\
(\mathbf{M P a})\end{array}$ & $\begin{array}{c}\sigma_{\mathbf{u}} \\
(\mathbf{M P a})\end{array}$ & $\begin{array}{c}\varepsilon_{\text {uniform }} \\
(\boldsymbol{\%})\end{array}$ & $\begin{array}{c}\varepsilon_{\text {total }} \\
(\boldsymbol{\%})\end{array}$ & HV 20 \\
\hline 0X & 337 & 481 & 15 & 30 & 140 \\
$1 \mathrm{X}$ & 561 & 589 & 3.1 & 11 & 196 \\
$1 \mathrm{XH}$ & 544 & 573 & 3.9 & 22 & 205 \\
$4 \mathrm{XH}$ & 651 & 682 & 3.7 & 22 & 269 \\
$1 \mathrm{XH+CR}(70)$ & 747 & 769 & 3.4 & 19 & 196 \\
$4 \mathrm{XH+CR}(70)$ & 779 & 877 & 3.3 & 18 & 205 \\
CR(70) & 605 & 702 & 2.4 & 12 & 229 \\
CR(90) & 697 & 797 & 3.0 & 12 & 271 \\
Ti6-4 (F136) & $795 *$ & $860 *$ & $5 * *$ & $10 *$ & - \\
\hline
\end{tabular}

*Minimum value specified by ASTM F136; **estimated value-not specified by the standard.

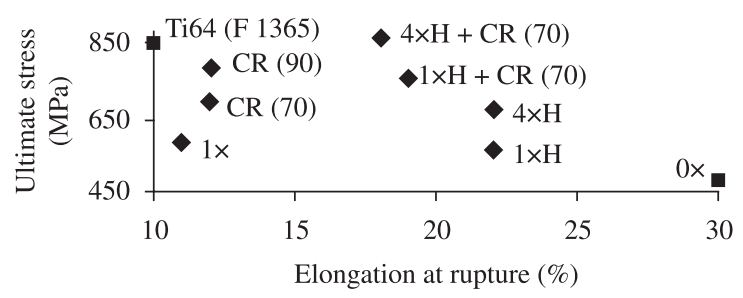

Figure 1. Ultimate stress and elongation at rupture for Grade $2 \mathrm{Ti}$ submitted to different DPS conditions, compared to Grade $2 \mathrm{Ti}$ (annealed) and Ti6Al4V. a number of requirements regarding mechanical properties, see the above mentioned Standard. It must be recalled here that $\mathrm{F} 543^{20}$ is a document that, among other guidelines, provides performance considerations and a test method for measuring mechanical properties in torsion of metallic bone screws that are implanted into bone. Thus, the method is intended to measure the uniformity of the product tested, or to compare the mechanical properties of different, yet similarly sized products. These considerations make clear that the present results can only apply to the material; in other words, they intend to be a measure of the effects of SPD techniques on Ti Grade 2, which, eventually can be employed in the manufacture of bone screws. In order to associate the present results with the cortical screws performance requirements, two important parameters of said products must be defined:

- Maximum torque $\left(\mathrm{T}_{\max }\right)$-largest value of torque before screw failure in torsional shear, whose minimum value is equal to $2.3 \mathrm{Nm}$;

- Breaking angle $\left(\theta_{\mathrm{f}}\right)$-angle of rotation when the screw fails in tension; it is related to the material ductility; minimum angle is $180^{\circ}$.

From tensile tests data it is possible to calculate torsional properties related to strength and ductility, making use of the following Equations 1 and $2^{21}$.

$\sigma_{u}=\frac{3 \sqrt{3} T_{u}}{2 \pi(D / 2)^{3}}$

$\varepsilon_{e q}=\frac{D \theta}{2 L \sqrt{3}}$

where $\sigma_{u}$ is the equivalent maximum tensile stress, $T_{u}$ the maximum torque, $\varepsilon_{\mathrm{eq}}$ the von Mises strain, D the torsion test cylindrical sample diameter and $\mathrm{L}$ its gauge length. When $\varepsilon_{\text {eq }}=\varepsilon_{\text {uniform }}$, the angle $\theta$ is equal to the angle corresponding to $\mathrm{T}_{\mathrm{u}}$, and here will be named twist angle $\left(\theta_{\mathrm{u}}\right)$. It must be pointed out that Equation 1 is valid only when $\sigma=\sigma_{u}$. Since the above equations require the introduction of values for $\mathrm{D}$ and $\mathrm{L}$, the

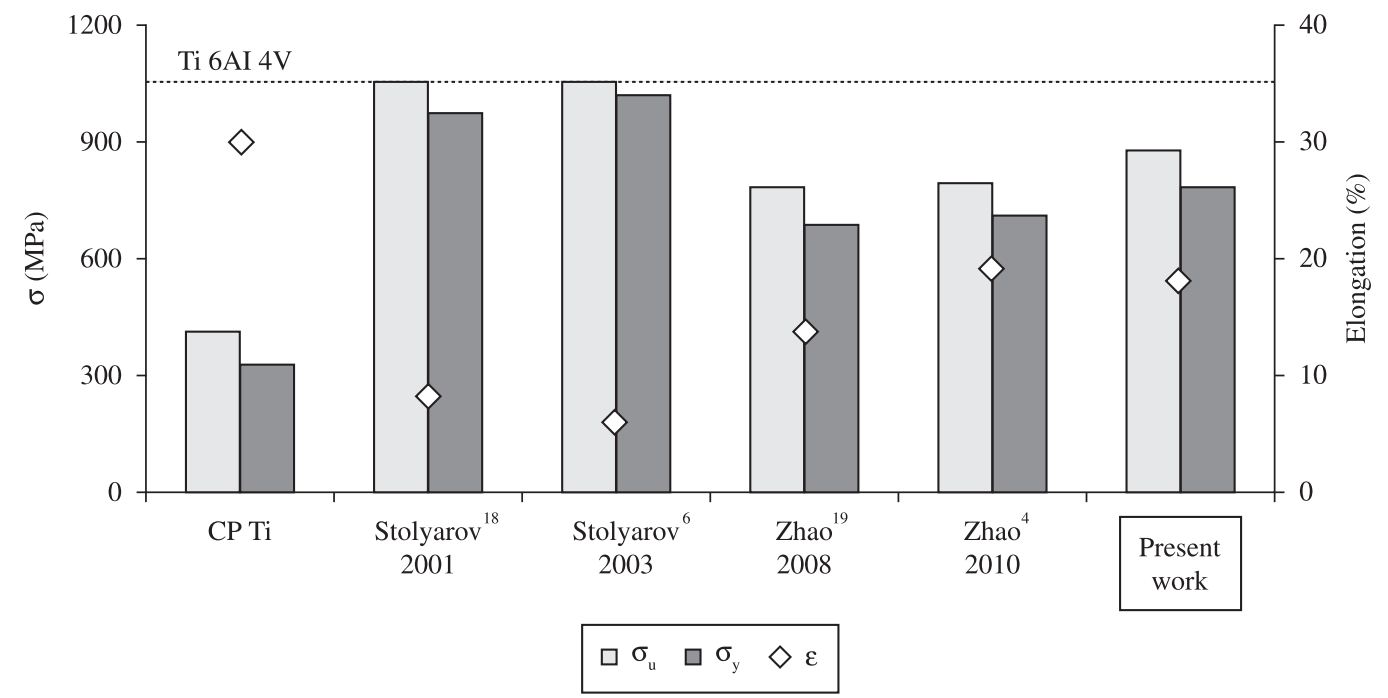

Figure 2. Comparison of the tensile behavior here obtained with those of other investigators. Dashed line indicates the ultimate strength of the Ti6-4 alloy $4,6,18,19$. 


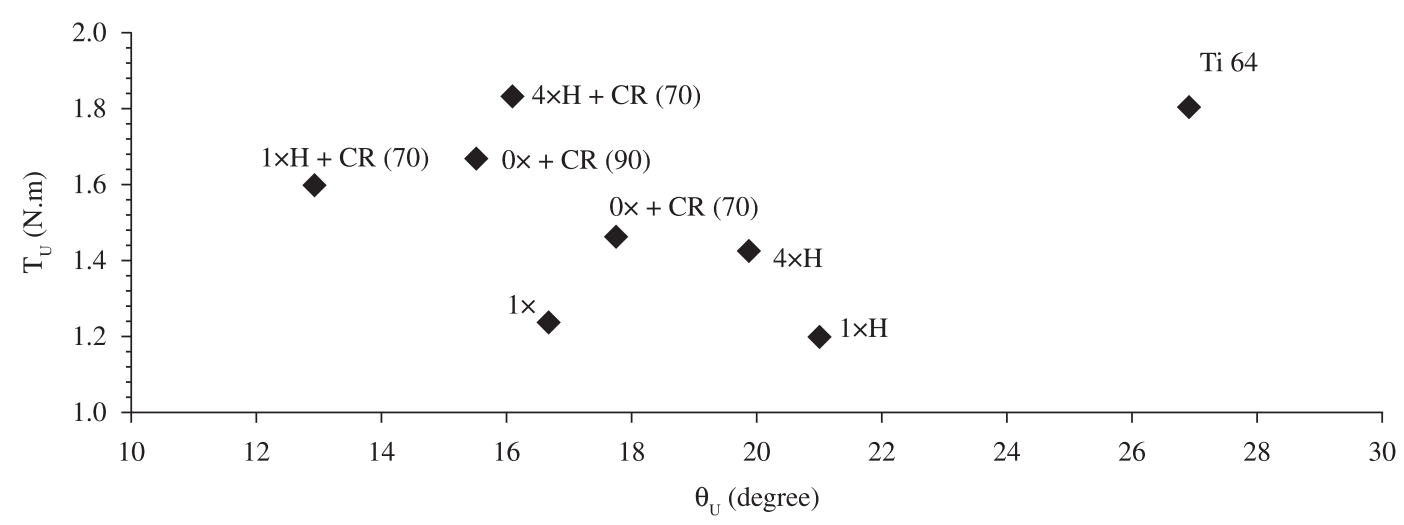

Figure 3. Torque and twist angle corresponding to $\sigma=\sigma_{u}$ for Grade $2 \mathrm{Ti}$, under different processing condition and compared with the alloy torsional properties.

present data can be compared with the values of maximum torque and breaking angle prescribed by the ASTM F543 Standard ${ }^{20}$ by employing the relevant dimensions of type HA 3.5 cortical screws.

Figure 3 relates data on maximum torque with the correspondent twist angle $\theta_{u}$, calculated by Equations 1,2, in which the $\sigma_{u}$ and $\varepsilon_{\text {uniform }}$ values (Table 3 ) were introduced. $\mathrm{D}$ and $\mathrm{L}$ were respectively taken as $2.4 \mathrm{~mm}$ (the screw core diameter of cortical screws type HA 3.5) and $6.5 \mathrm{~mm}$ (about five times the thread pitch). It must be stressed that the resulting $T_{u}$ and $\theta_{u}$ refer to a smooth torsion specimen made of Grade $2 \mathrm{Ti}$, having dimensions equal to the cortical screw type HA 3.5 but not to the screw itself.

Figure 3 shows that the $4 \mathrm{XH}+\mathrm{CR}(70)$ sample has slightly higher $\mathrm{T}_{u}$ than that of Ti6-4 alloy, but it must be taken into account that in the present calculation D was considered equal to the core diameter of the screw. In fact, the screw thread is a helical groove on a cylindrical surface, so that the screw cross section is about $22 \%$ higher than the circular core, thus the resulting torque may have been underestimated. On the other hand, when dealing with real cortical screws, stress concentration originated by the threads must be considered; therefore, the actual torque may be lowered, thus counteracting the above mentioned underestimation. However, inspection of the ASTM F543 Standard ${ }^{21}$ shows that in most types the screw profiles are relatively smooth, a feature devised to reduce stress concentration as much as possible. At any rate, precise data on maximum torque and breaking angle of real screws can only be obtaining by following the test method provided by the Standard, and this is outside the scope of the present paper.

Furthermore, although a requirement regarding the twist angle calculated by Equation 2 (valid within the uniform deformation range), is absent in the ASTM Standard ${ }^{20}$ the present value was compared to an estimated $\theta_{u}$ for Ti6-4 (using Equation 2). Figure 3 shows that values of all twist angles for $\mathrm{Ti}$ are lower than that estimated for the alloy, but Table 3 shows that the non-uniform elongation at rupture in tension for $\mathrm{Ti}$, that is, $\varepsilon_{\text {total }}-\varepsilon_{\text {uniform }}$, is much higher than that estimated for the alloy, namely 14 against $5 \%$, an indication of lower strain rate sensitivity of the former material. That this behavior is advantageous for the SPD Ti in terms of the breaking angle $\theta_{\mathrm{f}}$ specified by the Standard was confirmed by some recent experimental data obtained on smooth torsion samples ${ }^{9}$, in which the breaking angle for Ti4X and the Ti6-4 alloy were equal to $253^{\circ}$ and $230^{\circ}$, respectively.

\section{Conclusions}

1. The tensile strength difference between Grade $2 \mathrm{Ti}$ and the alloy Ti6-4, was reduced from 379 to $-17 \mathrm{MPa}$ by four ECAP passes performed at $300{ }^{\circ} \mathrm{C}$ and a subsequent $70 \%$ thickness reduction by cold rolling;

2. In terms of strength enhancement, a thickness reduction of $70 \%$ by cold rolling is similar to four ECAP passes at $300{ }^{\circ} \mathrm{C}$. Although all modes of deformation show ductility losses with respect to the non-deformed sample, losses are more severe when only cold rolling was employed;

3. Sample $4 \mathrm{XH}+\mathrm{CR}(70)$ has the same maximum torque than the 6-4 alloy, but its twist angle is $\approx 40 \%$ lower. Suggestions can be made that the low strain rate sensitivity of Grade 2 Ti may benefit the breaking angle; and

4. Results show that on a material-to-material comparison, ECAP processed Grade $2 \mathrm{Ti}$ can replace the Ti6-4 alloy as a construction material for medical bone screws. 


\section{References}

1. McKay GC, Mcnair R, MacDonald C and Grant MH. Interactions of orthopaedic metals with an immortalized rat osteoblast cell line. Biomaterials. 1996; 17:1339-1344. http://dx.doi.org/10.1016/0142-9612(96)88681-9

2. Park JW, Kim Y-J, Park CH, Lee D-H, Ko YG Jang J-H et al. Enhanced osteoblast response to an equal channel angular pressing-processed pure titanium substrate with micro rough surface topography. Acta Biomaterialia. 2009; 5:3272-3280. PMid:19426841. http://dx.doi.org/10.1016/j. actbio.2009.04.038

3. Valiev RZ, Stolyarov VV, Rack HJ and Lowe TC. SPDprocessed ultra-fine grained ti materials for medical applications. In: Shrivastava S, ed. Medical Device Materials. Cleveland: ASM; 2004. 362 p.

4. Zhao X, Yang X, Liu X, Wang X and Langdon TG. The processing of pure $\mathrm{Ti}$ (Grade 1) through multiple passes of ECAP at room temperature. Materials Science and Engineering. 2010; A527:6335-6339.

5. Semiatin SL, Segal VM, Goforth, RE, Frey ND and DeLo DP. Workability of commercial-purity titanium and 4340 steel during equal channel angular extrusion at cold-working temperatures. Metallurgical and Materials Transactions.1999; 30A:425-1435.

6. Stolyarov VV, Zhu YT, Alexandrov IV, Lowe TC and Valiev RZ. Grain refinement and properties of pure Ti processed by warm ECAP and cold rolling. Materials Science and Engineering. 2003; A343:43-50.

7. Chen YJ, Li YJ, Walmsley JC, Dumoulin S, Gireesh SS, Armada $S$ et al. Quantitative analysis of grain refinement in titanium during equal channel angular pressing. Scripta Materialiaialia. 2011; 64:904-907. http://dx.doi.org/10.1016/j. scriptamat.2011.01.030

8. Terhune SD, Swisher DL, Oh-Ishi K, Horita Z, Langdon TG and McNelley TR. An Investigation of Microstructures and Grain-Boundary Evolution during ECA Pressing of Pure Aluminum. Metallurgical and Materials Transactions. 2002; 33A:2173-2184. http://dx.doi.org/10.1007/s11661-002-0049-x

9. Mendes Filho AA. Incremento de resistência mecânica em titânio comercialmente puro por extrusão em canal angular aplicação em implantes ortopédicos. [Dissertação]. São Carlos: Universidade Federal de São Carlos; 2010.

10. Xu C, Furukawa M, Horita $Z$ and Langdon TG. The evolution of homogeneity and grain size refinement during equal-channel angular pressing: a model for grain refinement in ECAP. Materials Science and Engineering. 2005; A398:66-76.

11. Reihanian M, Ebrahimi R, Moshksar MM, Terada D and Tsuji N. Microstructure quantification and correlation with flow stress of ultrafine grained commercially pure Al fabricated by equal channel angular pressing (ECAP). Materials Characterization. 2008; 59:312-1323. http://dx.doi. org/10.1016/j.matchar.2007.11.006

12. Lian J, Valiev RZ and Baudelet B. On the enhanced grain growth in ultrafine grained metals. Acta Metallurgica et Materialia. 1995; 43:4165-4170. http://dx.doi.org/10.1016/09567151(95)00087-C

13. Prados, EF. Deformação em canal angular de uma liga Al-4\% Cu: efeito dos mecanismos de endurecimento na resistência mecânica e ductilidade. [Tese]. São Carlos: Universidade Federal de São Carlos; 2011.

14. Balyanov A, Kutnyakova J, Amirkhanova NA, Stolyarov VV, Valiev RZ, Liao XZ et al. Corrosion resistance of ultra finegrained Ti. Scripta Materialia. 2004; 51:225-229. http://dx.doi. org/10.1016/j.scriptamat.2004.04.011

15. American Society for Testing and Materials - ASTM. ASTM B 348:2010: Standard Specification for Titanium and Titanium Alloy Bars and Billets. ASTM; 2010.

16. Hayashi $M$, Hoshimura $H$, Ishii $M$ and Harada $H$. Recrystallization behavior of commercially pure titanium during hot rolling. Tokyo: Nippon Steel Corp Tokyo; 1994. Nippon Steel Technical Report, n. 6. UDC669.295 -174:621.7.061.2.

17. American Society for Testing and Materials - ASTM. ASTM F136: Standard Specification for Wrought Titanium-6 Aluminum-4 Vanadium ELI (Extra Low Interstitial) Alloy for Surgical Implant Applications (UNS R56401). ASTM.

18. Stolyarov VV, Zhu YT, Lowe TC and Valiev RZ. Microstructure and properties of pure Ti processed by ECAP and cold extrusion. Materials Science and Engineering. 2001; A303:82-89.

19. Zhao X, Fu W Yang X and Langdon, TG. Microstructure and properties of purte titanium processed by equalchannel angular pressing at room temperature. Scripta Materialia. 2008; 59:542-545. http://dx.doi.org/10.1016/j. scriptamat.2008.05.001

20. American Society for Testing and Materials - ASTM. ASTM F543: Standard Specification and Test Methods for Metallic Medical Bone Screws. ASTM; 2002.

21. Dieter GE. Mechanical Metallurgy. McGraw-Hill; 1986. 